\title{
In Vitro Study on Bone Heating during Drilling of the Implant Site: Material, Design and Wear of the Surgical Drill
}

\author{
Juan Carlos Bernabeu-Mira *, Hilario Pellicer-Chover, Miguel Peñarrocha-Diago $\unrhd$ and \\ David Peñarrocha-Oltra (D) \\ Oral Surgery Unit, Department of Stomatology, Faculty of Medicine and Dentistry, University of Valencia, \\ Oliag Gascó 1, 46010 Valencia, Spain; hilariopellicer@gmail.com (H.P.-C.); miguel.penarrocha@uv.es (M.P.-D.); \\ david.penarrocha@uv.es (D.P.-O.) \\ * Correspondence: juancarlos_bernabeu@hotmail.com; Tel.: +34-963864175
}

Received: 6 March 2020; Accepted: 17 April 2020; Published: 19 April 2020

check for updates

\begin{abstract}
Objective: An in vitro study was made to compare mean thermal variation according to the material, design and wear of the surgical drills used during dental implant site preparation. Material and methods: Three study groups (stainless steel drills with straight blades; diamond-like carbon-coated drills with straight blades; and diamond-like carbon-coated drills with twisted blades) were tested to compare material, design and wear of the surgical drill in terms of overall mean values (complete sequence of drills) and specific mean values (each drill separately). The groups comprised four drills: initial, pilot, progressive and final drill. Implant site configuration was performed through an intermittent and gradual drilling technique without irrigation at $800 \mathrm{rpm}$ in standardized synthetic blocks. Maximum axial loading of two kilograms was controlled by an automatic press. Each surgical drill was submitted to 50 drillings and was sterilized every five uses. A thermographic camera analyzed the mean thermal changes. The software-controlled automatic press kept systematic drilling, axial loading and operational speed constant without any human intervention. Student's t-test, ANOVA and multiple linear regression models were performed. The level of significance was $5 \%(p=0.05)$. Results: The overall mean comparison between the stainless steel and diamond-like carbon-coated materials showed no statistically significant differences ( $p>0.05)$, though specific mean comparison showed statistically significant differences between the drills of the different groups $(p<0.05)$. The twisted blades exhibited less overall and specific mean thermal variation than straight blades for the progressive and final drills $(\mathrm{p}<0.01)$. In addition, the initial and pilot drills showed a greater mean thermal change than the progressive and final drills. The mean thermal variation was seen to increase during the 50 drillings. Conclusions: Within the limitations of this study, it can be concluded that the drill material did not significantly influence the overall mean thermal variation except for the pilot drill. The drill design affected overall and specific mean thermal variation since the twisted blades heated less than the straight blades. The initial and pilot drills increased the specific mean thermal variation with respect to the progressive and final drills. In addition, all drills in each group produced a gradual increase in mean temperature during the 50 drillings.
\end{abstract}

Keywords: bone heating; drilling; implant site; design; material; wear

\section{Introduction}

Standard protocols in implant dentistry involve the use of surgical drills to prepare implant sites. This generates an increase in temperature due to friction between the surgical drill and bone.

According to the literature, thermal osteonecrosis of the peri-implant bone may occur if the temperature stays above $47^{\circ} \mathrm{C}$ for one minute [1]. Controlling thermal trauma to bone due to 
drilling of the implant site is necessary to ensure survival of all cells and proteins implicated in the bone remodeling [2,3]. Bone overheating during drilling may cause early implant failure due to the accumulation of necrotic bone, fibrous tissue, bone sequestration, bacteria and inflammatory infiltrates around the implant [4]. To avoid this, most implant systems use irrigation as part of the drilling protocol. However, a randomized clinical trial has suggested that drilling without irrigation could be viable and comparable to drilling with irrigation in terms of bone loss and early implant failure at one year of follow-up [5]. This drilling technique without irrigation allows better visualization of the drilling area and better control of the drill and of bone harvesting. Therefore, optimizing the drilling system as much as possible to control thermal increments without the need for irrigation systems makes sense in order to keep bone below the critical temperature and thus prevent bone necrosis.

Many factors are involved in the thermal changes during drilling of the implant site: rotational speed, load or pressure, drilling technique, drilling depth, irrigation, drill material, drill design, drill wear and characteristics of the bone [6-8].

Thermal changes have been studied for a great variety of drill materials. The most widely studied material is stainless steel [6]. However, ceramics [9] and coated stainless steel such as diamond-like carbon-coated [10] or direct diamond-coated drills [11] have also been studied. The thermal changes associated to diamond-like carbon-coated drills have been investigated in a study [10] that found no statistically significant differences with respect to stainless steel drills.

The possible thermal changes have been analyzed in relation to certain design characteristics of the drills, such as the tip angle [12], cutter shape [13], number of cutting edges [12], magnitude of bone contact surface [14] and length of the active part [15]. However, none of the studies published to date have compared the temperature changes between straight and twisted blades.

Wear due to repeated use of the surgical drill has been recorded thermally in a number of studies [12,16], because the cutting efficiency and quality of conventional rotating drills for bone implant surgery would be affected. Thus, hard coatings are generally applied on the blades of these surgical drills, especially when precise cuttings and insert stability are required. An example is the diamond-like carbon-coated drill. This coating would improve cutting efficiency due to its greater hardness compared to stainless steel $[10,11]$.

The present study was carried out to compare the mean thermal differences between stainless steel and diamond-like carbon-coated drills, and between straight and twisted drill blades-and to analyze the thermal evolution of the drill during repeated use. The working hypothesis was that the material, design and wear of the surgical drill can influence mean thermal variation during drilling of the implant site.

\section{Material and Methods}

\subsection{Study Design}

The present in vitro study on the mean thermal changes during drilling of the implant site was carried out at the Research, Development and Innovation (I+D+I) Department of Ticare (Mozo-Grau, SA, Valladolid, España). No ethical approval was required since the study was performed on a standardized synthetic block. The study was reported following the CRIS (checklist for reporting in-vitro studies) [17].

Three implant drilling systems (Ticare, Mozo-Grau, SA, Valladolid, España) were evaluated (Table 1): stainless-steel drills with straight blades (SS-SB); diamond-like carbon-coated drills with straight blades (DLCC-SB); and diamond-like carbon-coated drills with twisted blades (DLCC-TB). The surgical drilling sequence comprised four drills in each group (Table 1). 
Table 1. Study groups and design characteristics of the surgical drills.

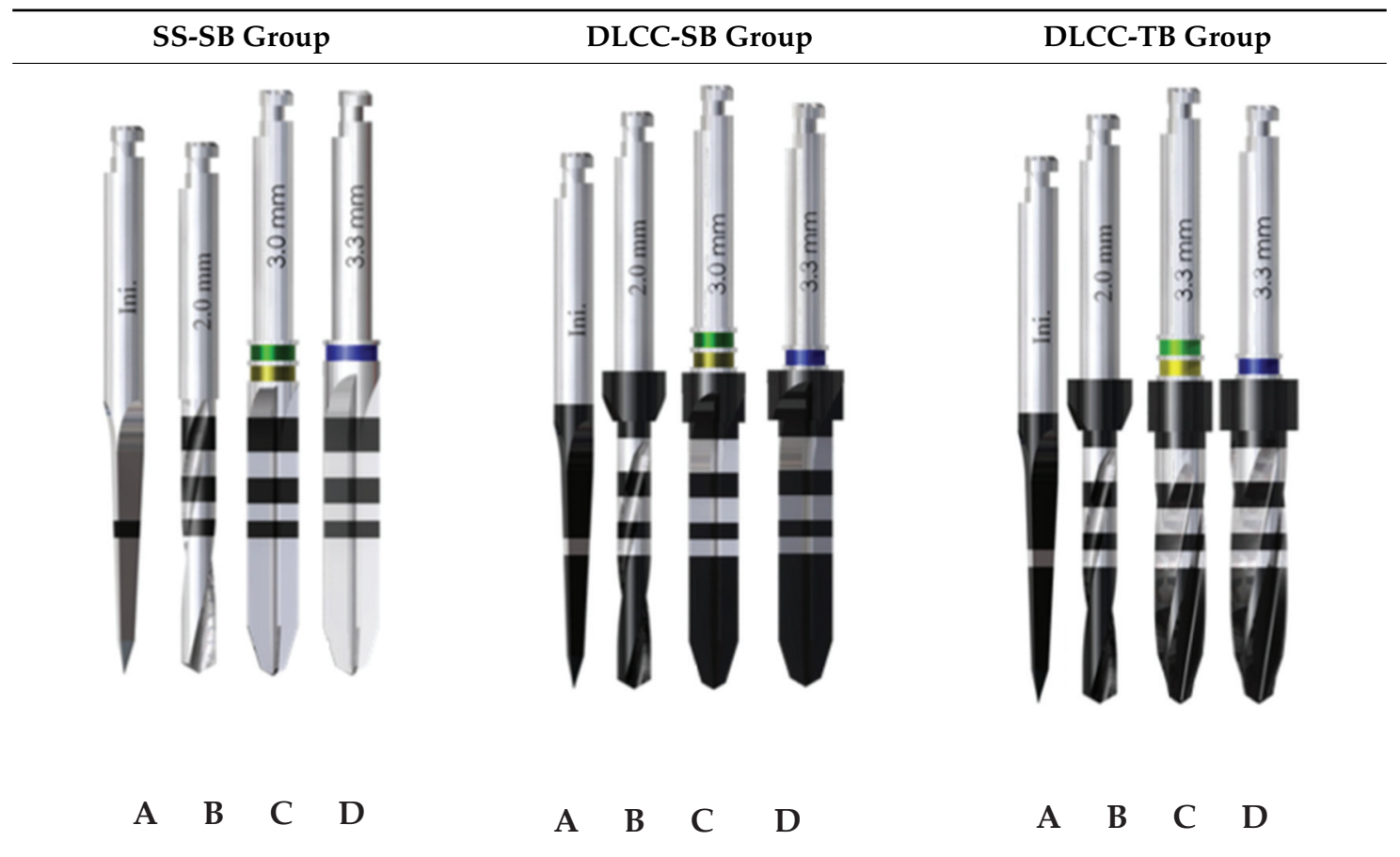

(A) Initial drill: $1.5-2 \mathrm{~mm} \emptyset$, tip angle $30^{\circ}$ and 3 cutting edges; (B) pilot drill: $2 \mathrm{~mm} \emptyset$, tip angle $120^{\circ}$ and 2 cutting edges; (C) progressive drill: $3 \mathrm{~mm} \emptyset, 120^{\circ}$ tip angle and 4 cutting edges; (D) final drill: $3.3 \mathrm{~mm} \emptyset, 120^{\circ}$ tip angle and 4 cutting edges( $\emptyset$ : diameter).

The drills of the SS-SB and DLCC-SB groups were produced with an identical design and only differed in the material component of the drills. In turn, the drills of the DLCC-TB and DLCC-SB groups were made of the same material and only differed in terms of the design of the blades for the progressive and final drills. Statistical comparison between the SS-SB and DLCC-SB groups yielded the results with respect to drill material, and the comparative analysis of the DLCC-SB and DLCC-TB groups evaluated the results with respect to drill design. It is important to note that the initial and pilot drills of the DLCC-SB and DLCC-TB groups were identical in all aspects.

\subsection{Operational Procedure}

The experimental parameters are shown in Table 2. All the operational variables were kept constant by the automatic press (ZwickRoell Z 2.5 ${ }^{\circledR}$, ZwickRoell, Ulm, Germany) equipped with a software system (ZwickRoell testXpert II V3.2 ${ }^{\circledR}$ ZwickRoell, Ulm, Germany). This machine applied constant axial loading to the drill through the head of contra-angle, controlling maximal axial loading, the drilling technique, drilling depth and operational speed $(\mathrm{mm} / \mathrm{min})$. This automated system was designed to perform multiple drillings in a reproducible, precise and controlled manner, without the direct intervention of an operator (Figure 1).

Each drill was used to perform 50 drillings with a total sample (n) of 600 drillings. The overall mean thermal variations between the SS-SB and DLCC-SB groups was measured as the mean of 200 drillings. The mean thermal variations between the DLCC-SB and DLCC-TB groups was measured as the mean of 100 drillings, since the initial and pilot drills were of the same design and material.

The drills were held by the non-active part through the corresponding support in order to preserve its integrity. In addition, the drills were sterilized every 5 uses. This sterilization process lasted a total of $30 \mathrm{~min}$ ( 5 min sterilization, $10 \mathrm{~min}$ drying and a vacuum phase) at a temperature of $134^{\circ} \mathrm{C}, 2$ bars of pressure and $2.5 \mathrm{~kg}$ of maximum loading. 
Table 2. Description of the experimental parameters.

\begin{tabular}{cc}
\hline \multicolumn{2}{c}{ Experimental Parameters } \\
\hline Parameter & Settings \\
Irrigation & None \\
Operational speed & $50 \mathrm{~mm} / \mathrm{min}$ \\
Rotation speed & $800 \mathrm{rpm}$ \\
Maximum axial load & $2 \mathrm{~kg}$ \\
\hline Maximum torque & $45 \mathrm{Ncm}$ \\
Depth of drilling & $11.5 \mathrm{~mm}$ \\
Drilling Technique & Intermittent and gradual \\
Pumping & 4 - and 8-mm depth \\
Sterilization & Every 5 drillings \\
\hline
\end{tabular}

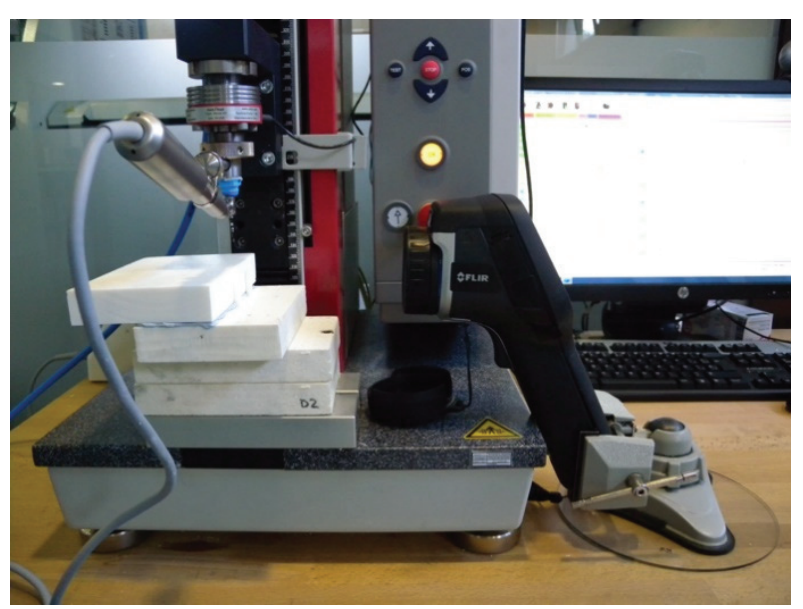

Figure 1. Experimental setup: automatic press (ZwickRoell Z $2.5^{\circledR}$, ZwickRoell, Ulm, Germany), standardized synthetic polyurethane blocks, FLIR E60bx ${ }^{\circledR}$ thermographic camera (FLIR Systems OÜ, Harju, Estonia) and drilling instruments.

\subsection{Standardized Synthetic Blocks}

The drillings were carried out on standardized synthetic block (Implant training plate, Biomechanicals Models ${ }^{\circledR}$, SelModels SL, Barcelona, Spain) with dimensions of $140 \times 90 \times 15 \mathrm{~mm}$. The block was formed by a constant cortical plate of $2 \mathrm{~mm}$ of thickness which covered the cancellous part to simulate human bone conditions type 2 according to the Lekholm and Zarb classification [18]. This structure guaranteed the equivalence of the different drilling sites respect to the density and the ratio between the cortical and cancellous portions [19]. Thermal conductivity of the standardized synthetic block $(0.3 \mathrm{~W} / \mathrm{m} / \mathrm{K})$ was analogous to the human bone (cortical bone: $0.29 \mathrm{~W} / \mathrm{m} / \mathrm{K}$ and cancellous bone: $0.16-0.34 \mathrm{~W} / \mathrm{m} / \mathrm{K}$ [20]). These thermal conductivity values assured that the measured thermal variation in this block was equivalent to those in human bone [21]. The room temperature was kept constant at $29^{\circ} \mathrm{C}$.

\subsection{Thermal Measurements}

The FLIR E60bx ${ }^{\circledR}$ thermographic camera (FLIR Systems OÜ, Harju, Estonia) measured the mean thermal changes. Its main features were image quality or thermal resolution $320 \times 240$ pixels, recordable temperature range $-20^{\circ} \mathrm{C}$ to $+120^{\circ} \mathrm{C}$ and thermal sensitivity $<0.045^{\circ}$ pixels or $<50 \mathrm{mK}$ NETD (noise equivalent temperature difference). This method has been used in other in vitro studies related to this topic [22-24].

To the effects of data collection, we calculated the thermal variation $(\Delta \mathrm{T})$ between the maximum temperature $\left(\mathrm{T}_{\mathrm{m}}\right)$ and the initial temperature $\left(\mathrm{T}_{0}\right)$, according to the mathematical expression: 
$\Delta \mathrm{T}=\mathrm{T}_{\mathrm{m}}-\mathrm{T}_{0}$. Thermal variation was expressed in degrees centigrade $\left({ }^{\circ} \mathrm{C}\right)$. The data were collected from video formats in order to be able to evaluate the thermal changes through a continuous temporal analysis. Such data collection was conducted by an independent researcher.

The overall mean thermal variation was the sum of all the thermal variations of all the drills of each respective group and was calculated to compare the design and material. The specific mean thermal variation was the sum of all the thermal variations of each drill within its respective group and was utilized to contrast comparisons between all the drills.

\subsection{Statistical Analysis}

The Student $\mathrm{t}$-test for independent sample was used to compare overall mean thermal variation according to the material and to the design. One-way analysis of variance (ANOVA) was used to evaluate the thermal effect between the drills of each group (specific mean thermal variation). Multiple comparisons were made with the Bonferroni test to avoid propagation of type I error. The thermal variation of drill wear over the number of uses was studied using multiple linear regression models. The level of significance used was $5 \%(p=0.05)$. For a Student $\mathrm{t}$-test with a confidence level of $95 \%$ and considering an effect size of 0.35 (small-medium), the resulting statistical power was 0.94 .

\section{Results}

The results of the statistical analysis are presented in Table 3 and Figure 2.

Table 3. Mean thermal variations of the stainless-steel drills with straight blades (SS-SB), diamond-like carbon-coated drills with straight blades (DLCC-SB) and diamond-like carbon-coated drills with twisted blades (DLCC-TB) groups.

\begin{tabular}{cccc}
\hline \multicolumn{1}{c}{ Groups } & SS-SB & DLCC-SB & DLCC-TB \\
\hline Specific mean $\Delta$ T of initial drills & $6.03 \pm 0.58$ & $6.11 \pm 0.58$ & $6.12 \pm 0.69$ \\
\hline Specific mean $\Delta \mathrm{T}$ of pilot drills & $7.42 \pm 0.68$ & $5.45 \pm 1.01$ & $5.46 \pm 1.08$ \\
\hline Specific mean $\Delta \mathrm{T}$ of progressive drills & $4.22 \pm 0.68$ & $4.65 \pm 0.53$ & $3.34 \pm 0.37$ \\
\hline Specific mean $\Delta \mathrm{T}$ of final drills & $4.16 \pm 0.45$ & $4.08 \pm 0.33$ & $3.14 \pm 0.51$ \\
\hline Overall mean $\Delta \mathrm{T}$ for drill material & $5.45 \pm 1.57$ & $5.07 \pm 1.70$ & - \\
\hline Overall mean $\Delta \mathrm{T}$ for drill design & - & $4.37 \pm 0.52$ & $3.24 \pm 0.48$ \\
\hline
\end{tabular}

$\Delta$ T: thermal variation.

\subsection{Drill Material}

There were no statistically significant differences in the overall mean values $(\mathrm{p}>0.05)$ between the SS-SB and DLCC-SB groups. The specific mean thermal variations were significantly greater for the pilot drill in the SS-SB group than in the DLCC-SB group and no statistically significant differences were observed among the other drills (Table 3 and Figure 2).

\subsection{Drill Design}

Statistically significant differences $(\mathrm{p}<0.01)$ were observed between the straight and twisted drill designs regarding the overall and specific mean thermal variations of the progressive and final drills (Table 3 and Figure 2).

\subsection{Drill Type}

The specific mean thermal variation of the initial and pilot drills was significantly greater than that of the progressive and final drills $(p<0.05)$ in all groups (Table 3 and Figure 2). 


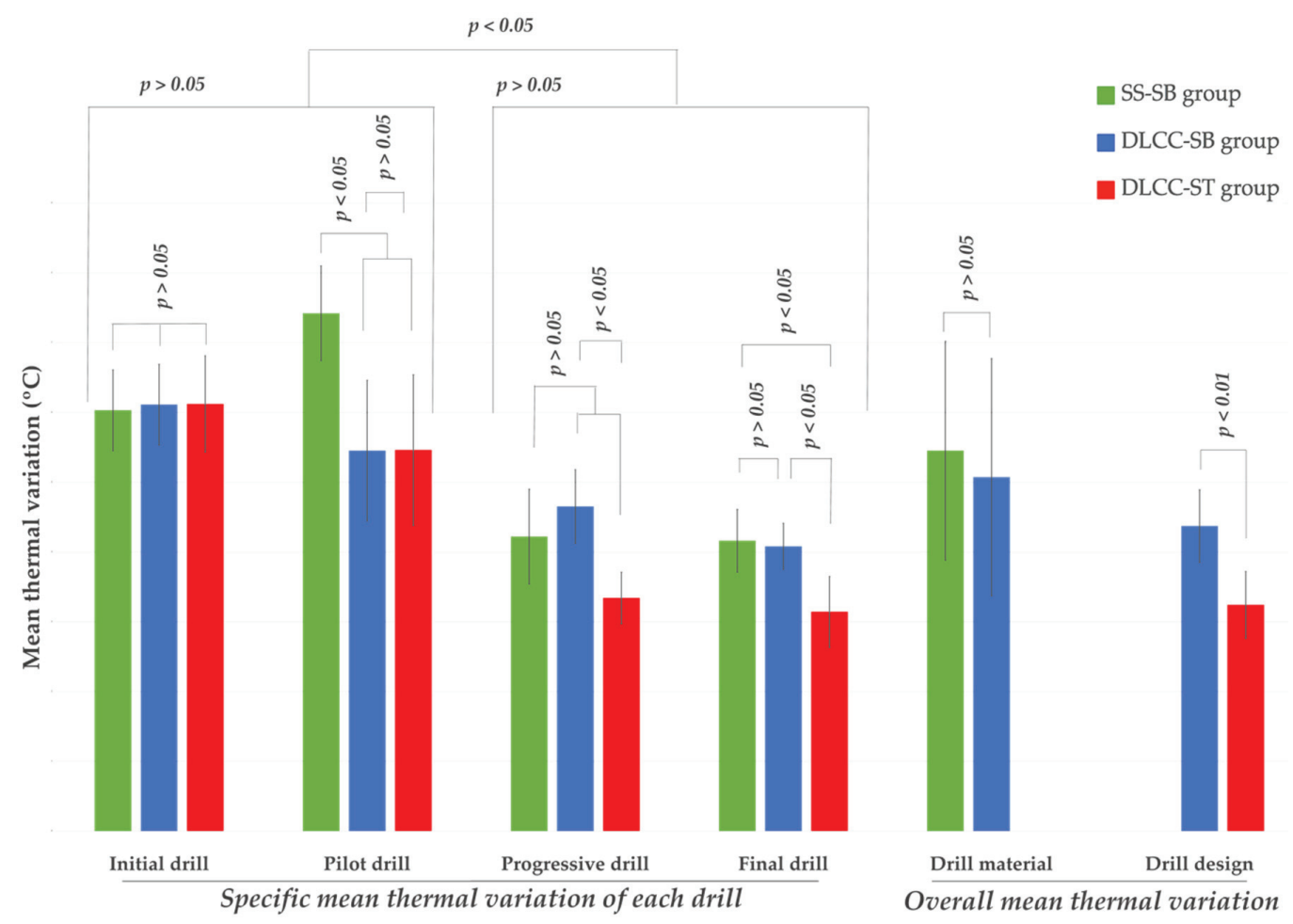

Figure 2. Graphic representation of the statistical analysis. The mean thermal variation of each drill and the overall mean thermal variation for each drill material and design are shown.

\subsection{Drill Wear}

Thermal variation increased according to a linear function over the 50 uses, independently of the drill material (Figure 3) and design (Figure 4).

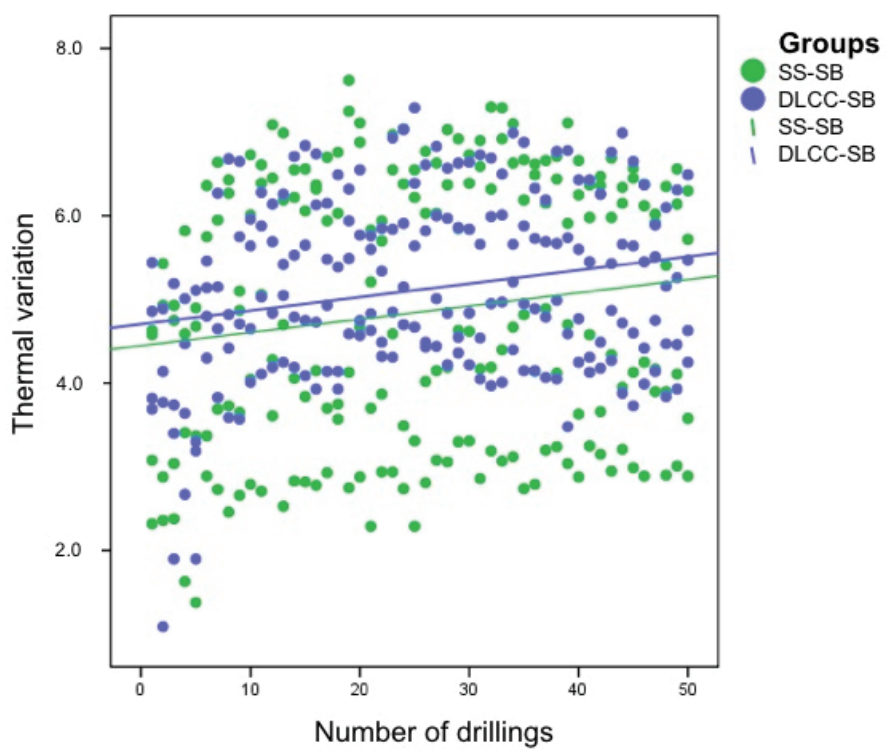

Figure 3. Thermal evolution over 50 drillings for the drills of the SS-SB and DLCC-SB groups. The green dots represent the thermal variation of each drill of the SS-SB group, and the blue dots represent the thermal variation of each drill of the DLCC-SB group. The green and blue lines correspond to the SS-SB group and DLCC-SB group, respectively, and represent multiple linear regression models of the thermal evolution of these groups. 


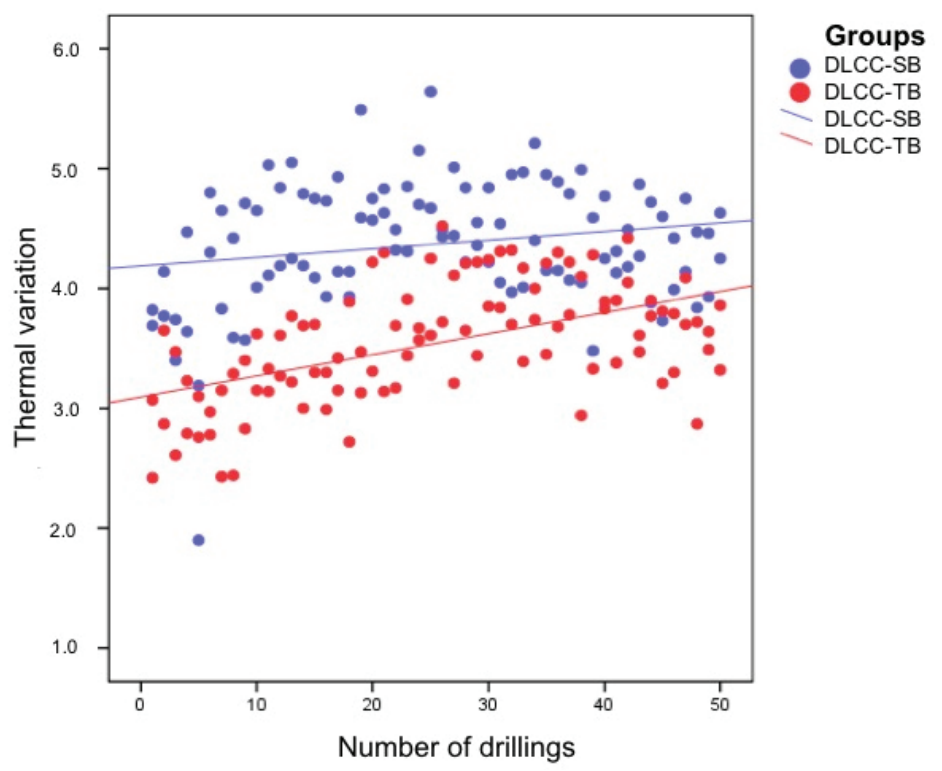

Figure 4. Thermal evolution over 50 drillings for the drills of the DLCC-SB and DLCC-TB groups. The blue dots represent the thermal variation of the progressive and final drills of the DLCC-SB group, and the red dots represent the thermal variation of the progressive and final drills of the DLCC-TB group. The blue and red lines correspond to the DLCC-SB group and DLCC-TB group, respectively, and represent multiple linear regression models of the thermal evolution of the progressive and final drills of these groups.

\section{Discussion}

The present in vitro study analyzed different variables that affect thermal variation during drilling of the implant site, such as the material, design and wear of the surgical drill. This subject is of crucial importance since overheating of the implant site may lead to thermal osteonecrosis [1] and early dental implant failure [4].

In our study, the overall mean thermal difference between the stainless steel and diamond-like carbon-coated drills was not statistically significant. Other authors have compared others types of materials and have reported no statistically significant changes in mean thermal variation during drilling [25-27]. Hochscheidt et al. [10] reported a higher mean temperature with diamond-like carbon-coated drills than with stainless steel drills- though the difference failed to reach statistical significance. The mentioned study drilled bovine ribs with a different cortical thickness of between 2-3 $\mathrm{mm}$, and the temperature was monitored with a thermocouple, which may affect the measurements [21-28]. The present study overcame the limitations of the thermal measurement method with infrared thermography and the of drilling medium with the use of standardized synthetic blocks [21-28]. The thermal conductive discrepancy between the tested materials could cause different heat concentrations in the friction zone [22] and distinct dissipation of the heat through the drill $[10,24,29]$. However, these factors do not appear to be sufficiently influential to result in statistically significant differences in overall mean thermal variation between the tested materials.

The cutting design of the drill blades showed statistically significant differences in our study, with twisted blades producing less mean thermal variation than straight blades. These significant differences can probably be explained by higher cutting efficiency and better removal of the bone chips with twisted drills $[14,15]$. No previous studies have compared these blade designs; direct comparisons are therefore not possible.

In the present study, drill wear significantly increased the mean thermal changes after 50 drillings and 10 sterilization cycles in all groups. The thermal change increments in this study were significantly different, in concordance with the literature [30,31]. A study [31] has analyzed wear based on scanning electron microscope analysis, revealing that repeated drill use deteriorates the physical 
and mechanical surface properties of the surgical drill. This mean thermal increase occurred in all types of materials $[9,10,26,32]$. The 10 sterilization cycles could be influenced by thermal variations, as evidenced by another study with the use of electron microscopy [33].

In our study, the mean thermal change of the initial and pilot drills increased significantly compared to the progressive and final drills, as also reported by other studies [34,35]. The first drills (initial and pilot) of the stepwise drilling procedure drill most of the material laterally and in depth, while the last drills of the sequence (progressive and final) only drill a smaller amount of material laterally $[34,35]$. However, other authors have reported that the last drills of greater diameters conferred greater thermal changes [24]. The pilot drill of the stainless-steel system showed a greater increase in mean thermal variation than the pilot drill of the diamond-like carbon-coated system. Differences between the tested materials in terms of hardness [10], cutting efficiency [16] or thermal conductivity $[25,29]$ seem to be more important in the most demanding heat-related drilling phases such as the pilot drill (with a combination of lateral drilling and up to maximum drilling depth). These differences may not have a significant impact in less demanding situations such as when the initial, progressive and final drills are used. More studies are needed to elucidate the cause of the lesser thermal effect of the pilot drill, which is the greatest generator of heat.

Three methodological aspects are important to ensure the reproducibility and accuracy of tests of this kind: the drilling medium, the thermal measurement method and automatization of the operational procedure. Regarding the drilling medium, most previously published studies used several drilling media, such as bovine ribs with dissimilar densities and relationships between the cortical and cancellous bone. This fact could affect the resulting thermal variations [21]. Some studies have tried to eliminate this limitation through the use of synthetic blocks [14,23]. This drilling media has a uniform density, equivalent mechanical characteristic [14] and thermal conductivity to the human bone density [21]. Regarding thermal measurement, the most commonly used methods have been thermocouples and thermography [6]. Harder et al. [28] compared thermocouples and thermography in an in vitro study involving a total sample size of 160 drillings. They concluded that thermography more accurately reflected the intraosseous thermal changes during implant site preparation versus thermocouples, including when irrigation methods are used. However, interpositioning between irrigation and the thermographic camera could interfere with thermal measurement in the drilling zone [36]. A limitation that distances our study from the real life standard clinical drilling protocols is the absence of an irrigation method due to the use of infrared thermography [37]. Regarding automatization of the operational procedure in this study, some authors have adopted the same procedure using automatic machines without direct human intervention in order to ensure constant operational speed $(\mathrm{mm} / \mathrm{min})$, axial loading and timing during all drillings $[21,28]$.

\section{Conclusions}

Within the limitations of this study, it can be concluded that the drill material did not significantly influence the overall mean thermal variation, except for the pilot drill. The drill design affected overall and specific mean thermal variation since the twisted blades heated less than the straight blades. The initial and pilot drills increased the specific mean thermal variation with respect to the progressive and final drills. In addition, all drills in each group produced a gradual increase in mean temperature during the 50 drillings.

Author Contributions: Conceptualization, J.C.B.-M., H.P.-C., M.P.-D. and D.P.-O.; methodology, J.C.B.-M., H.P.-C., M.P.-D. and D.P.-O.; software, J.C.B.-M., H.P.-C., M.P.-D. and D.P.-O.; validation, H.P.-C., M.P.-D. and D.P.-O.; formal analysis, J.C.B.-M. and D.P.-O.; investigation, J.C.B.-M. and D.P.-O.; resources, M.P.-D. and D.P.-O.; data curation, J.C.B.-M. and D.P.-O.; writing-original draft preparation, J.C.B.-M. and D.P.-O.; writing-review and editing, J.C.B.-M., H.P.-C., M.P.-D. and D.P.-O.; visualization, J.C.B.-M., H.P.-C., M.P.-D. and D.P.-O.; supervision, H.P.-C., M.P.-D. and D.P.-O.; project administration, M.P.-D. and D.P.-O.; funding acquisition, M.P.-D. and D.P.-O. All authors have read and agreed to the published version of the manuscript 
Funding: This research received no external funding.

Acknowledgments: The authors wish to thank Arturo Álvaro Carballido for this technical advice regarding the use of the press and thermal camera.

Conflicts of Interest: The authors declare that they have no conflicts of interest.

\section{References}

1. Eriksson, A.; Albrektsson, T. Temperature threshold levels for heat-induced bone tissue injury: A vital-microscopic study in the rabbit. J. Prosthet. Dent. 1983, 50, 101-107. [CrossRef]

2. Slaets, E.; Carmeliet, G.; Naert, I.; Duyck, J. Early Trabecular Bone Healing Around Titanium Implants: A Histologic Study in Rabbits. J. Periodontol. 2007, 78, 510-517. [CrossRef]

3. Bahat, O.; Sullivan, R.M. Parameters for successful implant integration revisited part I: Immediate loading considered in light of the original prerequisites for osseointegration. Clin. Implant. Dent. Relat. Res. 2010, 12 (Suppl. 1), e2-e12. [CrossRef] [PubMed]

4. Piattelli, A.; Piattelli, M.; Mangano, C.; Scarano, A. A histologic evaluation of eight cases of failed dental implants: Is bone overheating the most probable cause? Biomaterials 1998, 19, 683-690. [CrossRef]

5. Pellicer-Chover, H.; Peñarrocha-Oltra, D.; Aloy-Prosper, A.; Sanchis-Gonzalez, J.-C.; Peñarrocha-Diago, M.; Peñarrocha-Diago, M. Comparison of peri-implant bone loss between conventional drilling with irrigation versus low-speed drilling without irrigation. Medicina Oral Patología Oral y Cirugia Bucal 2017, 22, e730-e736. [CrossRef] [PubMed]

6. Möhlhenrich, S.; Modabber, A.; Steiner, T.; Mitchell, D.A.; Hölzle, F. Corrigendum to "Heat generation and drill wear during dental implant site preparation: Systematic review". Br. J. Oral Maxillofac. Surg. 2016, 54, 117. [CrossRef] [PubMed]

7. Mishra, S.K.; Chowdhary, R. Heat Generated by Dental Implant Drills During Osteotomy-A Review. J. Indian Prosthodont. Soc. 2014, 14, 131-143. [CrossRef] [PubMed]

8. Tehemar, S.H. Factors affecting heat generation during implant site preparation: A review of biologic observations and future considerations. Int. J. Oral Maxillofac. Implant. 1999, 14, 127-136.

9. Oliveira, N.; Alaejos-Algarra, F.; Mareque-Bueno, J.; Ferres-Padro, E.; Hernandez-Alfaro, F. Thermal changes and drill wear in bovine bone during implant site preparation. A comparative in vitro study: Twisted stainless steel and ceramic drills. Clin. Oral Implant. Res. 2012, 23, 963-969. [CrossRef]

10. Hochscheidt, C.J.; Shimizu, R.H.; Andrighetto, A.R.; Moura, L.M.; Golin, A.L.; Hochscheidt, R.C. Thermal Variation During Osteotomy With Different Dental Implant Drills. Implant. Dent. 2017, 26, 73-79. [CrossRef]

11. Wadkar, P.P.; Khalap, S.; Shetty, D.; Gupta, A.; Shetty, A.; Dharmadhikari, S. A novel, new generation drill coating for osteotomy site preparation. Indian J. Dent. Res. 2019, 30, 767-771. [CrossRef] [PubMed]

12. E Chacon, G.; Bower, D.L.; Larsen, P.E.; McGlumphy, E.; Beck, F.M. Heat Production by 3 Implant Drill Systems After Repeated Drilling and Sterilization. J. Oral Maxillofac. Surg. 2006, 64, 265-269. [CrossRef] [PubMed]

13. Gehrke, S.A.; Júnior, J.S.A.; Martínez, C.P.-A.; Fernandez, M.P.R.; Maté Sánchez de Val, J.E.; Calvo-Guirado, J.L. The influence of drill length and irrigation system on heat production during osteotomy preparation for dental implants: An ex vivo study. Clin. Oral Implant. Res. 2016, 29, 772-778. [CrossRef] [PubMed]

14. Oh, H.J.; Wikesjo, U.M.; Kang, H.S.; Ku, Y.; Eom, T.G.; Koo, K.T. Effect of implant drill characteristics on heat generation in osteotomy sites: A pilot study. Clin. Oral Implant. Res. 2011, 22, 722-726. [CrossRef] [PubMed]

15. Sannino, G.; Capparè, P.; Gherlone, E.F.; Barlattani, A. Influence of the Implant Drill Design and Sequence on Temperature Changes During Site Preparation. Int. J. Oral Maxillofac. Implant. 2015, 30, 351-358. [CrossRef]

16. Ercoli, C.; Funkenbusch, P.; Lee, H.-J.; E Moss, M.; Graser, G.N. The influence of drill wear on cutting efficiency and heat production during osteotomy preparation for dental implants: A study of drill durability. Int. J. Oral Maxillofac. Implant. 2004, 19, 335-349.

17. Krithikadatta, J.; Gopikrishna, V.; Datta, M. CRIS Guidelines (Checklist for Reporting In-vitro Studies): A concept note on the need for standardized guidelines for improving quality and transparency in reporting in-vitro studies in experimental dental research. J. Conserv. Dent. 2014, 17, 301-304. [CrossRef] 
18. Chen, Y.-C.; Hsiao, C.-K.; Ciou, J.-S.; Tsai, Y.-J.; Tu, Y.-K. Effects of implant drilling parameters for pilot and twist drills on temperature rise in bone analog and alveolar bones. Med Eng. Phys. 2016, 38, 1314-1321. [CrossRef]

19. Lekholm, U.; Zarb, G.A. Patient selection and preparation. In Tissue-Integrated Prostheses: Osseointegration in Clinical Dentistry, 1st ed.; Branemark, P.-I., Zarb, G.A., Albrektsson, T., Eds.; Quintessence: Chicago, IL, USA, 1985; pp. 199-210.

20. Calttenburg, R.; Cohen, J.; Conner, S.; Cook, N. Thermal properties of cancellous bone. J. Biomed. Mater. Res. 1975, 9, 169-182. [CrossRef]

21. Strbac, G.D.; Giannis, K.; Unger, E.; Mittlbock, M.; Watzek, G.; Zechner, W. A novel standardized bone model for thermal evaluation of bone osteotomies with various irrigation methods. Clin. Oral Implant. Res. 2014, 25, 622-631. [CrossRef]

22. Scarano, A.; Piattelli, A.; Assenza, B.; Carinci, F.; Di Donato, L.; Romani, G.L.; Merla, A. Infrared thermographic evaluation of temperature modifications induced during implant site preparation with cylindrical versus conical drills. Clin. Implant. Dent. Relat. Res. 2011, 13, 319-323. [CrossRef] [PubMed]

23. Oh, H.; Kim, B.; Kim, H.-Y.; Yeo, I.L.; Wikesjö, U.; Koo, K.-T. Implant Drill Characteristics: Thermal and Mechanical Effects of Two-, Three-, and Four-Fluted Drills. Int. J. Oral Maxillofac. Implant. 2017, 32, $483-488$. [CrossRef] [PubMed]

24. Möhlhenrich, S.; Abouridouane, M.; Heussen, N.; Hölzle, F.; Klocke, F.; Modabber, A. Thermal evaluation by infrared measurement of implant site preparation between single and gradual drilling in artificial bone blocks of different densities. Int. J. Oral Maxillofac. Surg. 2016, 45, 1478-1484. [CrossRef] [PubMed]

25. Harder, S.; Egert, C.; Wenz, H.-J.; Jochens, A.; Kern, M. Influence of the drill material and method of cooling on the development of intrabony temperature during preparation of the site of an implant. Br. J. Oral Maxillofac. Surg. 2013, 51, 74-78. [CrossRef]

26. Koo, K.-T.; Kim, M.-H.; Kim, H.-Y.; Wikesjo, U.M.; Yang, J.-H.; Yeo, I.L. Effects of Implant Drill Wear, Irrigation, and Drill Materials on Heat Generation in Osteotomy Sites. J. Oral Implant. 2015, 41, e19-e23. [CrossRef]

27. Pires, L.F.S.; Tandler, B.; Bissada, N.; Duarte, S. Comparison of heat generated by alumina-toughened zirconia and stainless steel burs for implant placement. Int. J. Oral Maxillofac. Implant. 2012, 27, 1023-1028.

28. Harder, S.; Egert, C.; Freitag-Wolf, S.; Mehl, C.; Kern, M. Intraosseous Temperature Changes During Implant Site Preparation: In Vitro Comparison of Thermocouples and Infrared Thermography. Int. J. Oral Maxillofac. Implant. 2018, 33, 72-78. [CrossRef]

29. Moshiri, Z.; Roshanaei, G.; Vafaei, F.; Kadkhodazadeh, M. Evaluation the effect of drill type on heat generation in implant drilling site. Res. J. Med. Sci. 2013, 7, 118-122.

30. Basiaga, M.; Paszenda, Z.; Szewczenko, J.; Kaczmarek, M. Influence of surgical drills wear on thermal process generated in bones. Acta Bioeng. Biomech. 2013, 15, 19-23.

31. Scarano, A.; Carinci, F.; Quaranta, A.; Di Iorio, D.; Assenza, B.; Piattelli, A. Effects of bur wear during implant site preparation: An in vitro study. Int. J. Immunopathol. Pharmacol. 2007, 20 (Suppl. 1), 23-26. [CrossRef]

32. Sumer, M.; Misir, A.F.; Telcioglu, N.T.; Guler, A.U.; Yenisey, M.; Misır, A.F. Comparison of Heat Generation During Implant Drilling Using Stainless Steel and Ceramic Drills. J. Oral Maxillofac. Surg. 2011, 69, 1350-1354. [CrossRef] [PubMed]

33. Jochum, R.M.; A Reichart, P. Influence of multiple use of Timedur-titanium cannon drills: Thermal response and scanning electron microscopic findings. Clin. Oral Implant. Res. 2000, 11, 139-143. [CrossRef]

34. Abboud, M.; Delgado-Ruiz, R.A.; Kucine, A.; Rugova, S.; Balanta, J.; Calvo-Guirado, J.L. Multistepped Drill Design for Single-Stage Implant Site Preparation: Experimental Study in Type 2 Bone. Clin. Implant. Dent. Relat. Res. 2015, 17 (Suppl. 2), e472-e85. [CrossRef] [PubMed]

35. Bogovič, V.; Svete, A.; Bajsić, I. Effects of a drill diameter on the temperature rise in a bone during implant site preparation under clinical conditions. Proc. Inst. Mech. Eng. Part H: J. Eng. Med. 2016, 230, 907-917. [CrossRef] 
36. Markovic, A.; Misic, T.; Mancic, D.; Jovanovic, I.; Scepanovic, M.; Jezdic, Z. Real-time thermographic analysis of low-density bone during implant placement: A randomized parallel-group clinical study comparing lateral condensation with bone drilling surgical technique. Clin. Oral. Implant. Res. 2014, 25, 910-918. [CrossRef]

37. Lucchiari, N.; Frigo, A.C.; Stellini, E.; Coppe, M.; Berengo, M.; Bacci, C. In Vitro Assessment with the Infrared Thermometer of Temperature Differences Generated During Implant Site Preparation: The Traditional Technique Versus the Single-Drill Technique. Clin. Implant. Dent. Relat. Res. 2016, 18, 182-191. [CrossRef]

(C) 2020 by the authors. Licensee MDPI, Basel, Switzerland. This article is an open access article distributed under the terms and conditions of the Creative Commons Attribution (CC BY) license (http://creativecommons.org/licenses/by/4.0/). 